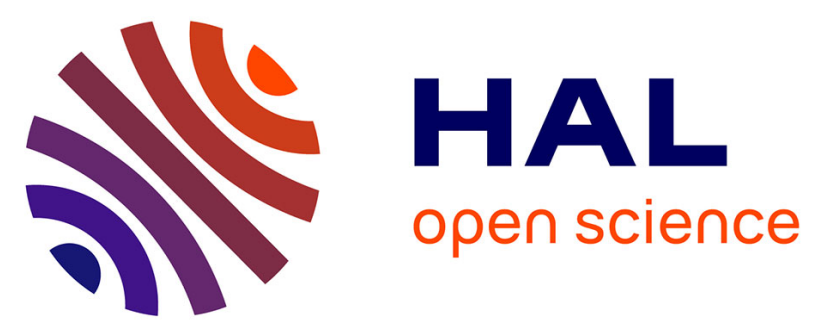

\title{
Thermo - mechanical properties of SPS produced self-healing thermal barrier coatings containing pure and alloyed MoSi 2 particles
}

Justyna Kulczyk-Malecka, Xun Zhang, James Carr, Franck Nozahic, Claude Estournès, Daniel Monceau, Alexandra L. Carabat, Willem G. Sloof, Sybrand van Der Zwaag, Philip J. Withers, et al.

\section{To cite this version:}

Justyna Kulczyk-Malecka, Xun Zhang, James Carr, Franck Nozahic, Claude Estournès, et al.. Thermo - mechanical properties of SPS produced self-healing thermal barrier coatings containing pure and alloyed MoSi 2 particles. Journal of the European Ceramic Society, 2018, 38 (12), pp.4268-4275. 10.1016/j.jeurceramsoc.2018.04.053 . hal-01810342

\section{HAL Id: hal-01810342 https://hal.science/hal-01810342}

Submitted on 7 Jun 2018

HAL is a multi-disciplinary open access archive for the deposit and dissemination of scientific research documents, whether they are published or not. The documents may come from teaching and research institutions in France or abroad, or from public or private research centers.
L'archive ouverte pluridisciplinaire HAL, est destinée au dépôt et à la diffusion de documents scientifiques de niveau recherche, publiés ou non, émanant des établissements d'enseignement et de recherche français ou étrangers, des laboratoires publics ou privés. 


\section{Open Archive TOULOUSE Archive Ouverte (OATAO)}

OATAO is an open access repository that collects the work of Toulouse researchers and makes it freely available over the web where possible.

This is an author-deposited version published in : http:/oatao.univ-toulouse.fr/ Eprints ID : 20141

To link to this article : DOI:10.1016/j.jeurceramsoc.2018.04.053

URL : https://doi.org/10.1016/j.jeurceramsoc.2018.04.053

To cite this version : Kulczyk-Malecka, Justyna and Zhang, Xun and Carr, James and Nozahic, Franck Monceau, Daniel $\leftrightarrows$ and Carabat, Alexandra L. and Sloof, Willem G. and van der Zwaag, Sybrand and Withers, Philip J. and Xiao, Ping Thermo - mechanical properties of SPS produced self-healing thermal barrier coatings containing pure and alloyed MoSi 2 particles. (2018) Journal of the European Ceramic Society, vol. 38 ( $\left.\mathrm{n}^{\circ} 12\right)$. pp. 42684275. ISSN 0955-2219

Any correspondence concerning this service should be sent to the repository administrator: staff-oatao@listes-diff.inp-toulouse.fr 


\title{
Thermo - mechanical properties of SPS produced self-healing thermal barrier coatings containing pure and alloyed $\mathrm{MoSi}_{2}$ particles
}

\author{
Justyna Kulczyk-Malecka ${ }^{\mathrm{a}, *}$, Xun Zhang ${ }^{\mathrm{a}}$, James Carr ${ }^{\mathrm{a}}$, Franck Nozahic ${ }^{\mathrm{b}, \mathrm{c}}$, Claude Estournès ${ }^{\mathrm{c}}$, \\ Daniel Monceau ${ }^{\mathrm{b}}$, Alexandra L. Carabat ${ }^{\mathrm{d}}$, Willem G. Sloof ${ }^{\mathrm{d}}$, Sybrand van der Zwaag ${ }^{\mathrm{e}}$, \\ Philip J. Withers ${ }^{\mathrm{a}}$, Ping Xiao ${ }^{\mathrm{a}}$ \\ a School of Materials, The University of Manchester, M13 9PL, UK

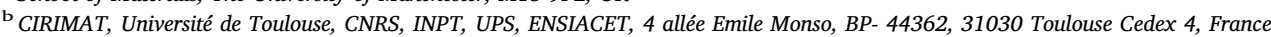 \\ ${ }^{\mathrm{c}}$ CIRIMAT, Université de Toulouse, CNRS, INPT, UPS, 118 Route de Narbonne, F-31062 Toulouse, France \\ d Department of Materials Science and Engineering, Delft University of Technology, Mekelweg 2, 2628 CD Delft, The Netherlands \\ e Faculty of Aerospace Engineering, Delft University of Technology, Kluyverweg 1, 2629 HS Delft, The Netherlands
}

Keywords:

Thermal barrier coatings (TBC)

Self - repairing materials

Mechanical properties

Ceramic composites

Life time extension

\begin{abstract}
A B S T R A C T
Yttria - partially stabilised zirconia (YPSZ) $\mathrm{MoSi}_{2}$ composites have been designed to prolong the lifetime of the matrix by self - healing cracks during thermal cycling. The healing reaction at high temperatures is based on the decomposition of $\mathrm{MoSi}_{2}$, leading to a volumetrically expanding reaction product, which seals the crack. In this work, coefficient of thermal expansion (CTE) and the fracture toughness of composites containing $\mathrm{MoSi}_{2}$ particles, produced by spark plasma sintering (SPS) have been compared to conventional YPSZ. The CTE mismatch between YPSZ and $\mathrm{MoSi}_{2}$ was found to be small, implying that thermally induced mismatch stresses will be small and the composites have a similar CTE to conventional YPSZ. Fracture toughness was found not to be affected by the particles and showed similar values to unreinforced YPSZ. Cracks introduced by indentation have been shown neither to prefer, or avoid, the particles suggesting that such a composite system is capable of autonomously activating the self - healing reaction.
\end{abstract}

\section{Introduction}

Thermal barrier coatings (TBCs) are applied onto the turbine blades and other thermo - mechanically loaded components in aircraft and industrial gas turbine engines to lower the operating temperature of the load bearing part of the component and thereby extending the lifetime of the engine. The coatings generally consist of well bonded thermally non - conductive yttria - partially stabilised zirconia (YPSZ) layers deposited onto the metallic components by atmospheric plasma spraying (APS) or electron beam physical vapour deposition (EB PVD). The thermal mismatch between the layers comprising the thermal barrier and the growth of thermally grown oxide (TGO) layer separating the base blade material and the deposited TBC layer, lead to the generation of stresses in the ceramic coating resulting in the initiation of micro - cracks. These micro - cracks subsequently grow and coalesce, leading to the failure of the coating by delamination [1-4]. To counteract this, molybdenum disilicide $\left(\mathrm{MoSi}_{2}\right)$ particles covered with a thin oxygen impermeable alumina shell have been embedded into YPSZ - based TBCs to provide a crack healing mechanism [5]. The healing mechanism is based on the oxidative decomposition of the particle once intersected by the crack and the reaction product filling and resealing the crack. The alumina shell is there to prevent premature particle decomposition due to oxygen transport through the uncracked porous YPSZ matrix. [6,7]. However, the presence of $\mathrm{MoSi}_{2}$ particles could affect important mechanical and thermal properties of the TBC. It has been reported that $\mathrm{MoSi}_{2}$ has a relatively low strength and fracture toughness below its brittle - to - ductile transition temperature $\left(\sim 1000^{\circ} \mathrm{C}\right)$. Therefore, it is important to understand the effect of embedded $\mathrm{MoSi}_{2}$ particles on the mechanical performance of YPSZ $\mathrm{MoSi}_{2}$ composites. $\mathrm{MoSi}_{2}$ also has a higher elastic modulus (approximately $400 \mathrm{GPa}$ ) and lower hardness (approximately 8-9 GPa) [8-11] than yttria - stabilised zirconia ( $\sim 200$ and $12-15 \mathrm{GPa}$, respectively) $[12,13]$. The potentially negative effect of the presence of the $\mathrm{MoSi}_{2}$ particles on the thermal conductivity of ТBC composite has been reported elsewhere [14] and was found to be acceptable up to a $\mathrm{MoSi}_{2}$ volume fraction of $10 \%$.

The very thin alumina shell surrounding the particle is unlikely to influence the macroscopical and thermo - mechanical properties 
significantly, but the integrity of the shell is crucial to its protective function. Maintaining its integrity during conventional TBC deposition via atmospheric plasma spraying is very hard and requires special process adjustments [15]. Hence, in the present work we focus on freestanding YPSZ material containing different volume fractions of $\mathrm{MoSi}_{2}$ particles manufactured by a spark plasma sintering (SPS) method. The healing particles in this work have been enriched with aluminium and boron ( $\mathrm{Al}$ and $\mathrm{B}$ contents were approx. 2 wt. \%). The $\mathrm{Al}$ doping is to lead to the autonomous formation of an alumina shell when the material is heated to a high temperature in an oxygen containing environment as shown in [6]. The co-doping with B is to increase the fluidity of the $\mathrm{SiO}_{2}$ facilitating crack healing at larger volumes $[16,17]$.

The aim of this work is to investigate the influence of embedding $\mathrm{MoSi}_{2}$ particles on the thermo - mechanical properties of the YPSZ and to test the potential self - healing ability of the material. Since the effect of porosity in APS TBCs on mechanical properties has been extensively studied and explained elsewhere [18-20] it has not been studied here. Based on the research reported here and on the results of parallel studies on crack healing modelling and thermal properties of the material $[14,21]$ future research to find an optimal combination of the $\mathrm{MoSi}_{2}$ volume fraction and particle morphology to achieve a significant lifetime improvement, while keeping the reduction in mechanical and thermal properties to a low level, will be accelerated.

\section{Experimental}

\subsection{Materials fabrication}

Disc shaped YPSZ samples with embedded $\mathrm{MoSi}_{2}$ based particles were prepared by spark plasma sintering (SPS). The powder mixtures were produced by mixing yttria - partially stabilized zirconia containing 7 wt. $\% \mathrm{Y}_{2} \mathrm{O}_{3}$ (YSZ Amperit 872, H.C. Starck, $\mathrm{D}_{50}$ of $45 \mu \mathrm{m}$ ) and molybdenum disilicide $\left(\mathrm{MoSi}_{2}, 99.5 \%\right.$ purity, ChemPur GmbH, $\mathrm{D}_{50}$ of $19 \mu \mathrm{m}$ ) for $24 \mathrm{~h}$ using a Turbula - type powder blender. The volume fraction of $\mathrm{MoSi}_{2}$ particles was varied between 5 and 20 vol. \%. Four types of $\mathrm{MoSi}_{2}$ particles were used: 1) technically pure $\mathrm{MoSi}_{2}$ particles, 2) $\mathrm{MoSi}_{2}$ particles containing 2 wt. \% Al, 3) $\mathrm{MoSi}_{2}$ particles containing 2 wt. \% B and 4) $\mathrm{MoSi}_{2}$ particles containing 2 wt. \% $\mathrm{Al}$ and $2 \mathrm{wt} \% \mathrm{~B}$. Prior to sintering, the YPSZ powder was downsized from $40 \pm 0.7 \mu \mathrm{m}$ to $7 \pm 0.3 \mu \mathrm{m}$ using a Retsch PM 100 planetary ball miller. Zirconia balls of $10 \mathrm{~mm}$ diameter were used as grinding media. The ball to powder mass ratio was kept to 3:1. The rotor speed was $300 \mathrm{rpm}$ and the milling time was $24 \mathrm{~h}$.

The final particle size distributions of YPSZ and the four types of $\mathrm{MoSi}_{2}$ particles were determined using a Malvern Master Sizer X laser diffraction instrument (Malvern Instruments Ltd., Worcestershire, UK). Prior to the measurements, the particles were ultrasonicated in water for $20 \mathrm{~min}$. Table 1 shows average particle sizes determined for four types of $\mathrm{MoSi}_{2}$ particles.

The composite materials were sintered using a Dr. Sinter SPS-2080 (SPS Syntex Inc., Kanagawa, Japan) available at the Plateforme Nationale CNRS de Frittage Flash (PNF2 - CNRS) located at Université Toulouse III Paul Sabatier (UT3). The powder mixtures were placed in an $80 \mathrm{~mm}$ diameter holder lined with a $0.200 \mathrm{~mm}$ thick graphite foil and mounted into the SPS equipment. SPS sintering was performed

Table 1

Average particle sizes of four types of $\mathrm{MoSi}_{2}$ particles embedded into YPSZ matrix.

\begin{tabular}{cc}
\hline Particle composition & Average particle size $[\mu \mathrm{m}]$ \\
\hline${\mathrm{Pure} \mathrm{MoSi}_{2}}^{2}$ & $18.0 \pm 0.3$ \\
$\mathrm{MoSi}_{2}+2$ wt. \% Al & $12.0 \pm 0.1$ \\
$\mathrm{MoSi}_{2}+2$ wt. \% B & $19.0 \pm 0.3$ \\
$\mathrm{MoSi}_{2}+2$ wt. \% Al and 2 wt. \% B & $14.0 \pm 0.9$ \\
\hline
\end{tabular}

under vacuum $\left(<10 \mathrm{~Pa}\right.$ ) with a fixed heating rate of $50^{\circ} \mathrm{C} / \mathrm{min}$ up to $1500{ }^{\circ} \mathrm{C}$ and an isothermal hold of $60 \mathrm{~min}$ under a constant uni - axial pressure of $40 \mathrm{MPa}$ applied from the beginning of the sintering cycle. A standard procedure of 12:2 (on/off $3.3 \mathrm{~ms}$ ) pulse sequence for the DC current was chosen for the sintering process. The regulation temperature of the SPS furnace was measured using an optical pyrometer focused on a small hole ( $3 \mathrm{~mm}$ in depth) located at the external surface of the graphite die. The sintering resulted in disc shaped samples $80 \mathrm{~mm}$ diameter and about $12 \mathrm{~mm}$ in thickness.

\subsection{Microstructural characterisation}

The microstructure of the samples was investigated by scanning electron microscopy (FEG - SEM, Quanta 650) using a backscatter electron (BSE) detector and light optical microscopy (LOM). Energy dispersive $\mathrm{X}$ - ray spectroscopy (EDX, Oxford Instruments) was used to determine the elemental composition of the material. The $\mathrm{MoSi}_{2}$ particle volume fractions of the embedded particles were evaluated by computerised image analysis using Avizo 9.2 software. The phase composition was obtained by $\mathrm{X}$ - ray diffraction (XRD, Philips X'Pert). Sintered samples were scanned from 20 to $852 \theta^{\circ}$ with 0.02 step size under $\mathrm{Cu} \mathrm{K} \alpha$ radiation.

\subsection{Materials testing}

The coefficient of linear thermal expansion (CTE) of the as - prepared composite samples was measured between room temperature and $1200{ }^{\circ} \mathrm{C}$ at $2.5^{\circ} \mathrm{C} / \mathrm{min}$ using a thermo - mechanical analyser (Setsys Evolution 16118 - Setaram). This brings a linear transducer into contact with the surface of the sample during heating and cooling under argon atmosphere for two consecutive thermal cycles. A thermocouple, positioned close to the sample was used to monitor the temperature. The average diameters and thicknesses of the cylindrical shaped specimens used for CTE measurements were $8 \mathrm{~mm}$ and $5 \mathrm{~mm}$, respectively. To prevent any contamination of the equipment by the specimens, two alumina plates with a thickness of $500 \mu \mathrm{m}$ were placed on either side of the specimen. A blank was measured with the alumina plates only and their contribution to the overall dilatation was subtracted prior to processing of the data.

Indentation fracture resistance values, $K_{I F R}$, of the YPSZ composite materials were determined by macro hardness test equipped with a Vickers indenter. Samples were indented under the load of $98 \mathrm{~N}$, a load which was selected after making sure that the extent of diagonal cracks at each indenter corner, $c$, was at least twice the length of the indent diagonal, $a$. Microstructure characterization techniques have also been used to investigate the propagation of mechanically induced cracks. The purpose of this study was to obtain insight into the interactions of the crack (crack deflection, crack stopping or interfacial cracking) with the healing particles for various volume fractions of healing particles in the composite material. To quantify the crack - particle interaction the micrographs were image analysed (IA). The counting methodology employed was as follows: when the crack has passed through a particle this event contributes ' 1 ' to the count; when the crack has only partially entered the particle, without passing it throughout, the count is increased by ' 0.5 '. The data obtained from IA gave an average number of interactions between a crack and the embedded particles as well as the average crack length segmented to be filled in between the particles.

\section{Results and discussion}

\subsection{Microstructure and phase identification}

Fig. 1 shows the LOM micrographs of the cross - sectioned composite samples. The particles are randomly distributed within the YPSZ matrix and vary in shape and size. From the micrographs, it seems that samples with the lowest volume percentage of healing particles show 

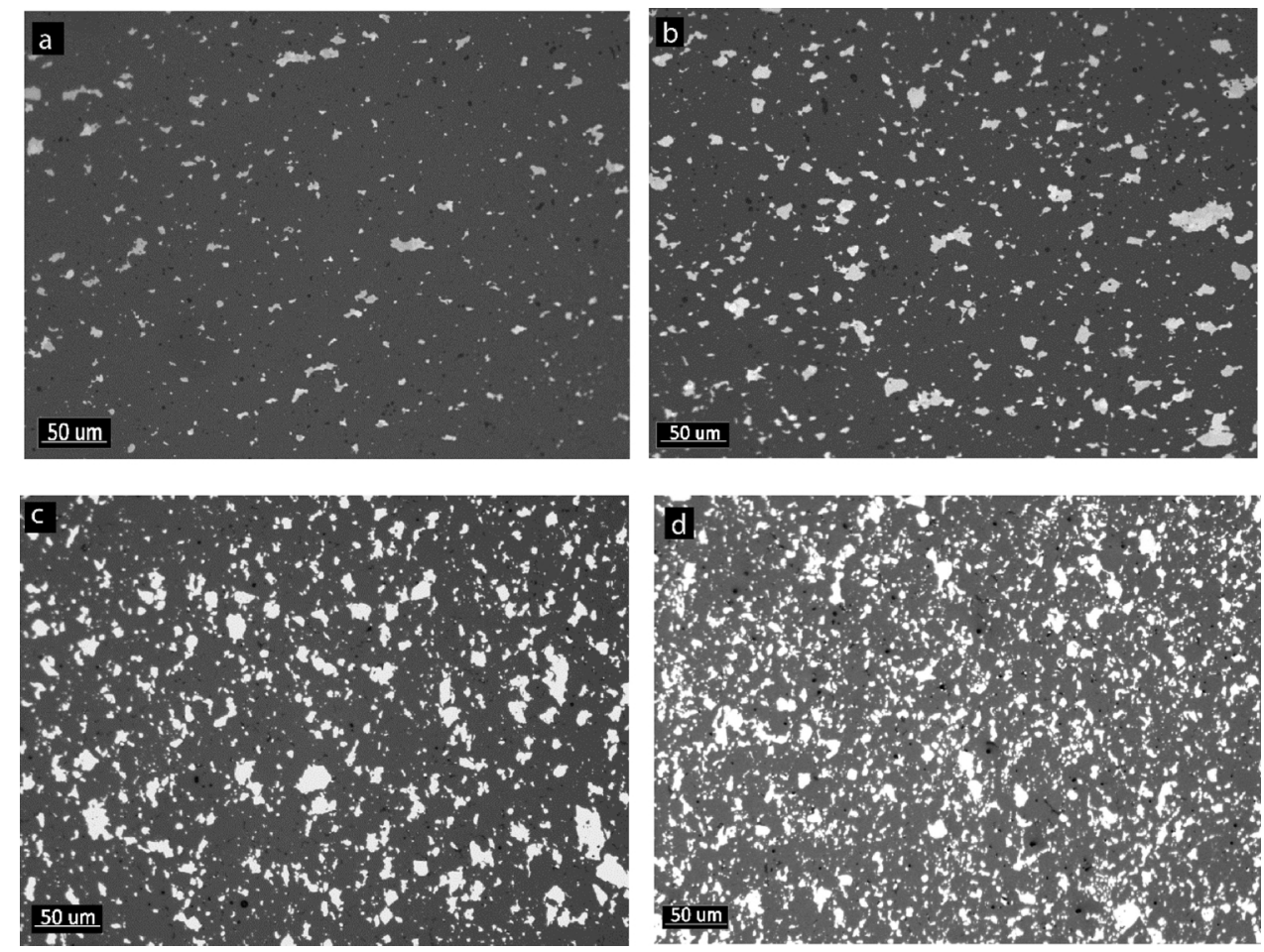

Fig. 1. Light optical micrographs of YPSZ composite samples produced by SPS containing (a) 5, (b) 10, (c) 15 and (d) 20 vol. $\%$ of MoSi $\mathbf{~}_{2}$ particles. The 'healing' particles appear as the white phase, whereas the YPSZ matrix is the grey phase.

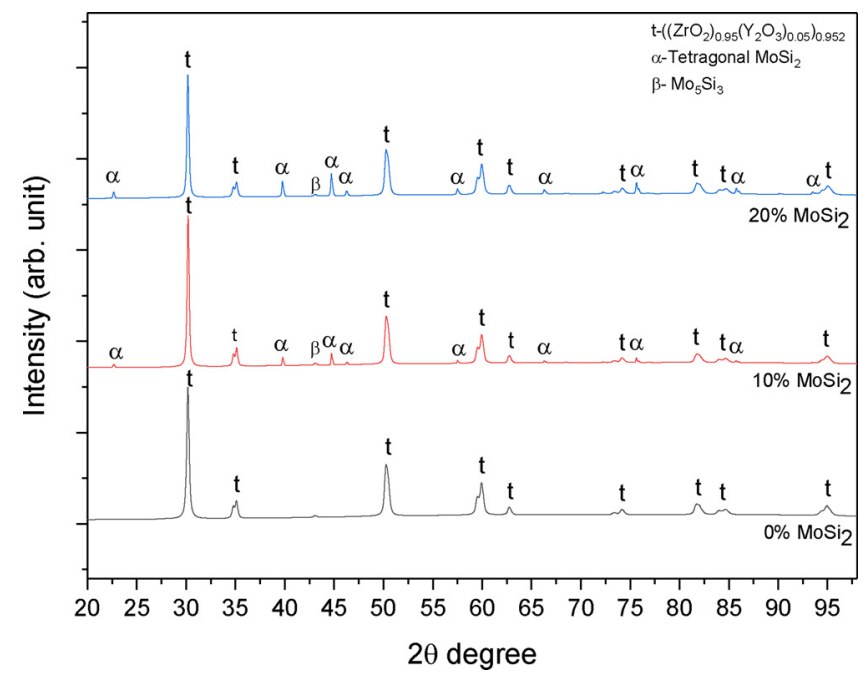

Fig. 2. XRD peak profiles collected from the samples containing 0,10 and 20 vol. \% of embedded $\mathrm{MoSi}_{2}$ particles. Peaks have been assigned to the different phases identified from the analysis.

Table 2

Area fraction of self - healing composites calculated based on the image analysis.

\begin{tabular}{ccccc}
\hline $\begin{array}{c}\text { Sample nominal } \\
\text { composition }\end{array}$ & 5 vol. \% & 10 vol. \% & 15 vol.\% & 20 vol. \% \\
\hline YPSZ $+\mathrm{MoSi}_{2}$ & $5.2 \pm 0.5$ & $9.1 \pm 0.5$ & $16.0 \pm 0.3$ & $23.9 \pm 0.6$ \\
$\mathrm{YPSZ}+\mathrm{MoSi}_{2} \mathrm{Al}$ & $4.9 \pm 0.5$ & $11.9 \pm 0.3$ & $16.6 \pm 1.3$ & $19.3 \pm 2.2$ \\
$\mathrm{YPSZ}+\mathrm{MoSi}_{2} \mathrm{~B}$ & $4.6 \pm 1.0$ & $10.7 \pm 0.7$ & $17.0 \pm 1.9$ & $19.3 \pm 0.8$ \\
$\mathrm{YPSZ}+\mathrm{MoSi}_{2} \mathrm{AlB}$ & $4.6 \pm 0.8$ & $8.6 \pm 0.8$ & $14.1 \pm 0.4$ & $26.2 \pm 0.9$ \\
\hline
\end{tabular}

smaller particles sizes, suggesting less agglomeration of the $\mathrm{MoSi}_{2}$ powder. This, in turn, could have the undesired effect of reducing the occurrence of the self - healing mechanism meaning that larger cracks could not be healed. XRD patterns of the as - produced samples reveal the presence of tetragonal zirconia and tetragonal $\mathrm{MoSi}_{2}$ phases (Fig. 2). Additionally, evidence of the $\mathrm{Mo}_{5} \mathrm{Si}_{3}$ minor phase was also detected. However, its content is minimal and its contribution to the material properties has been neglected. The measured volume fractions for the four composite grades are listed in Table 2 and the values correspond well with the target values.

\subsection{Thermal expansion of the particles}

Understanding the thermal expansion behaviour of composite materials is crucial when they are used in conjunction with other materials, as is the case in TBC coatings on turbine blades. Furthermore, Ceramic Matrix Composites (CMCs) reinforced with isolated particles may encounter thermal stresses induced by the inherent thermal mismatch between the matrix and the reinforcement [22]. Thus, ideally the thermal mismatch between them should be as small as possible to prevent cracking or interfacial delamination under thermal cycling conditions. In general, the thermal expansion is quantified by the coefficient of linear expansion (CTE), $\alpha(T)$, which is given by:

$\int_{L_{0}}^{L} \frac{d L}{L_{0}}=\int_{T_{0}}^{T} \alpha(T) d T$

where $T$ is the temperature, $L_{O}$ is the length of the sample at room temperature and $d L$ is the change in length over a temperature interval $d T$.

Fig. $3 \mathrm{a}$ and $\mathrm{b}$ show the thermal expansion of the sintered materials in the temperature range of $22-1200{ }^{\circ} \mathrm{C}$ for a $\mathrm{MoSi}_{2}$ volume fraction of $20 \%$. Very similar values were obtained for the $\mathrm{MoSi}_{2}$ based materials with different alloying elements (Fig. 3a) indicating that these elements do not have a large influence on the thermal expansion. As shown in Fig. 3b, it is evident that the addition of $20 \mathrm{vol}$. \% of $\mathrm{MoSi}_{2}$ only 

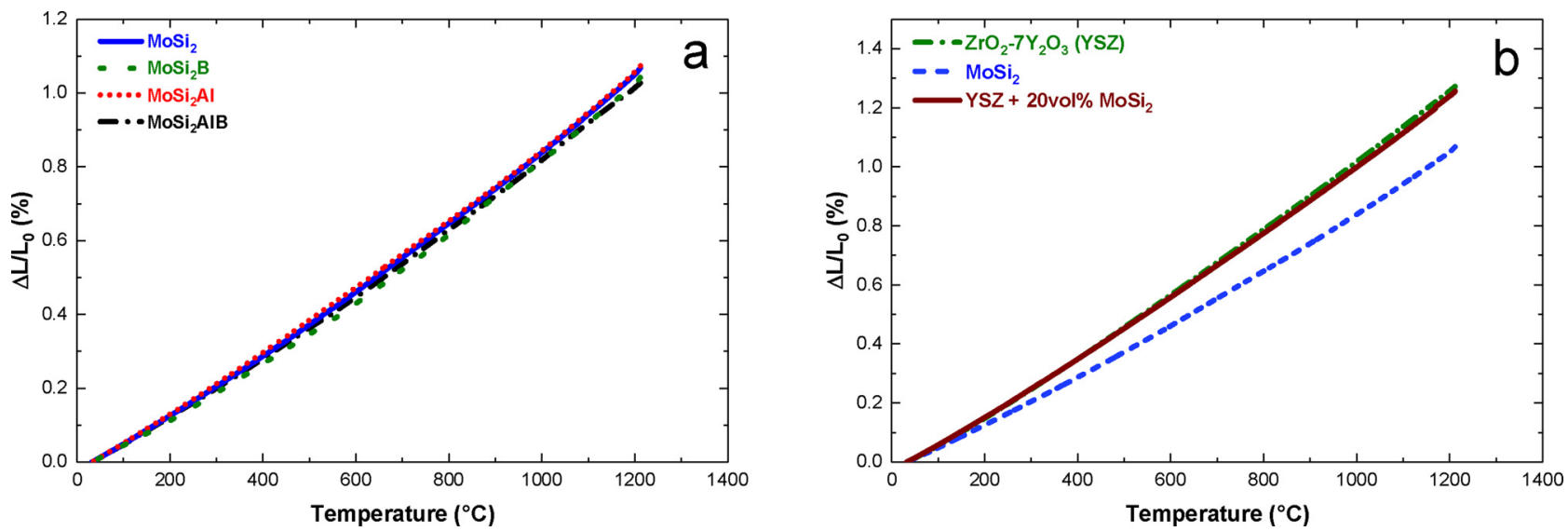

Fig. 3. Thermal expansion of the (a) $\mathrm{MoSi}_{2}$ based materials, (b) yttria - partially stabilized zirconia, MoSi ${ }_{2}$ and YPSZ embedded with 20 vol. $\% \mathrm{MoSi}_{2}$.

marginally reduced the thermal expansion of the composite in comparison with pure YPSZ suggesting they have a similar CTE to the matrix.

In order to extract the CTE as a function of temperature, the thermal expansion curves were approximated as polynomial functions according to:

$\frac{\Delta L}{L_{0}}=a T^{3}+b T^{2}+c T+d$

where $a, b, c$ and $d$ are experimental constants, $T$ is the temperature in $\mathrm{K}, L_{O}$ is the length at room temperature and $\Delta L=L-L_{O}$ is the thermal expansion for an increment of temperature $\Delta T=T-T_{O}\left(\mathrm{~T}_{0}=22^{\circ} \mathrm{C}\right)$.

For all fits to the experimental curve, a correlation coefficient greater than 0.9999 was obtained. The coefficient of linear thermal expansion (CTE) was then calculated by differentiating Eq. (2) with respect to $T$ :

$\alpha(T)=\frac{1}{L_{0}} \cdot \frac{d L}{d T}=3 a T^{2}+2 b T+c$

Fig. $4 \mathrm{a}$ and $\mathrm{b}$ shows the dependence of the CTE values for the four $\mathrm{MoSi}_{2}$ variants and the $\mathrm{MoSi}_{2}$ particles reinforced YPSZ matrix composites, respectively, as a function of temperature. The CTE values of pure $\mathrm{MoSi}_{2}$ and the alloyed $\mathrm{MoSi}_{2}$ materials are in good agreement for temperatures greater than $400{ }^{\circ} \mathrm{C}$, which might be attributed to the presence of additional $\mathrm{Mo}_{5} \mathrm{Si}_{3}$, MoB or hexagonal $\mathrm{MoSi}_{2}$ when alloying $\mathrm{B}$ or $\mathrm{Al}$ to $\mathrm{MoSi}_{2}$ (Fig. 4a). One can see that the CTE values for YPSZ and the $\mathrm{MoSi}_{2}$ particles reinforced YPSZ matrix composite are close to one another and higher than pure $\mathrm{MoSi}_{2}$ (Fig. 4b).

A simple rule of mixtures (RoM) was used to predict the thermal

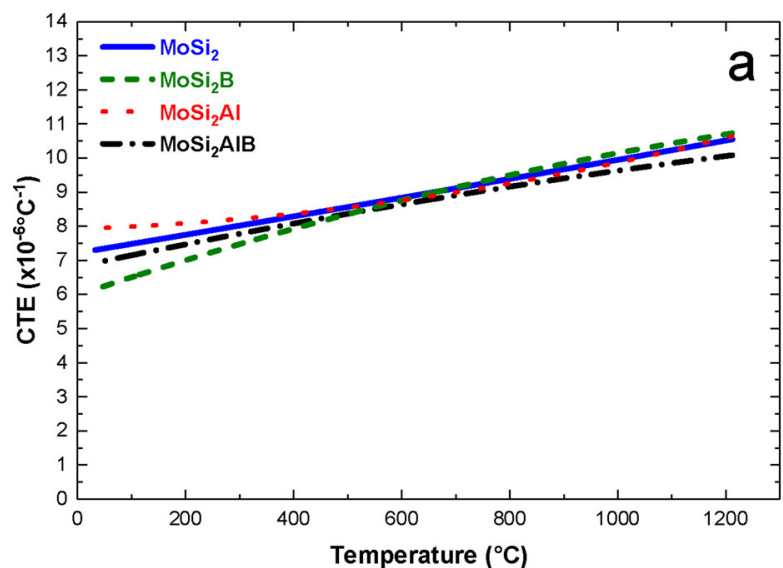

dilation of the particle reinforced composites (Fig. 4b). In this model, it is assessed that expansion of both materials is unhampered as if they were in series. One can observe that the experimental CTE values are in good agreement with the ones calculated with the rule of mixtures. Because the difference in CTE between particles and matrix is relatively small, more sophisticated models, such as Kerner's, Turner's or Schapery's [23-25] give similar results and therefore, are not plotted in Fig. 4b. The small difference in CTE between particles and matrix mean that only low level internal thermal mismatch stresses will be generated between the matrix (tension) and particles (compression) on cooling from the sintering temperature.

Consistent with this, no visible cracks were observed after sintering due to thermal stresses induced by a mismatch between the CTE values of $\mathrm{MoSi}_{2}$ and YPSZ, which is in agreement with other studies [26,27]. The low CTE mismatch also implies that the presence of $\mathrm{MoSi}_{2}$ particles are unlikely to generate cracks in the thermal barrier coating as it is thermally cycled, provided the ТВC coating itself does not have weak fracture planes such as splat boundaries. Furthermore, the composite TBC will have a similar mismatch to the underlying Ni-based substrate as conventional unreinforced TBCs.

\subsection{Mechanical properties}

Indentation fracture resistance of the composite materials was determined using micro - hardness test with a Vickers indenter. The values were calculated according to ASTM F2094 standard and are plotted in Fig. 5. Morrell [28] has pointed out that to correctly measure the fracture toughness of ceramic materials several experimental criteria

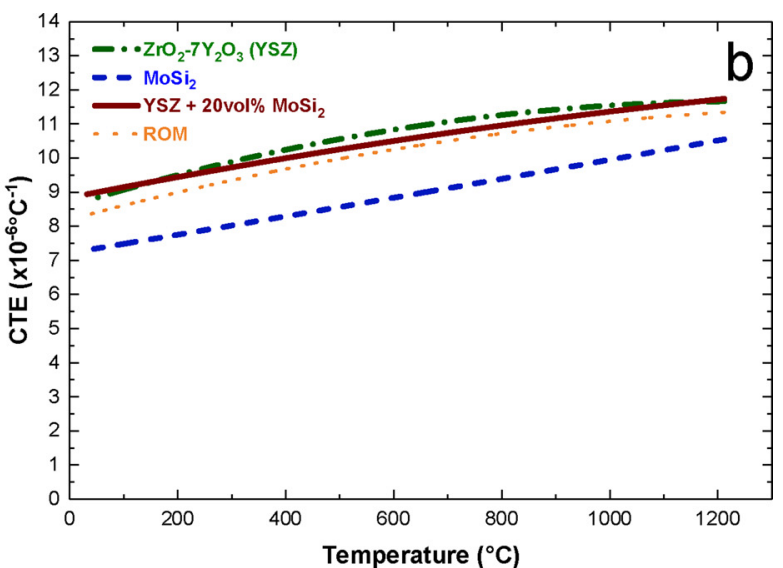

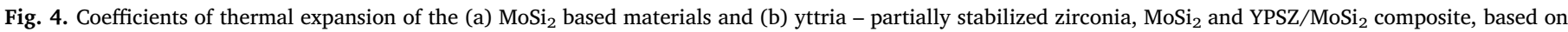
the sample length at room temperature. 


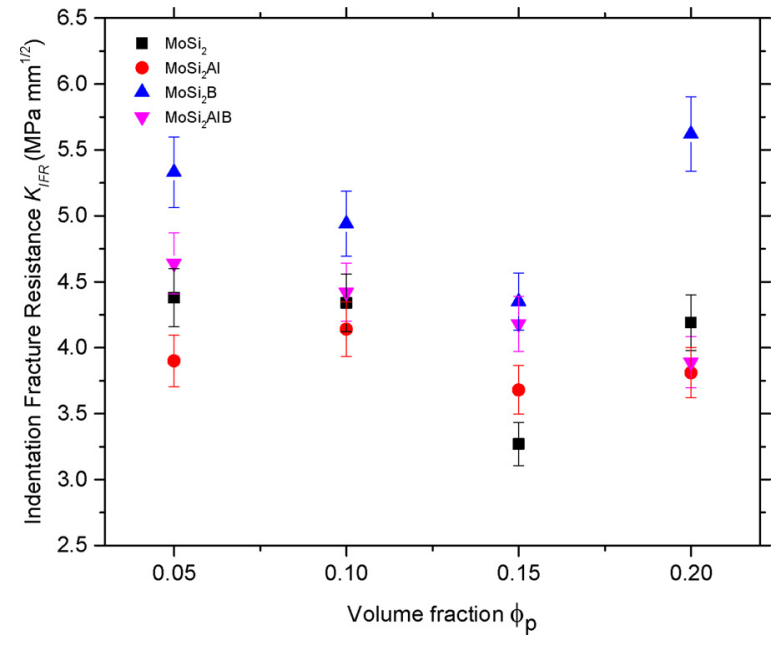

Fig. 5. Average indentation fracture resistance values calculated using Niihira's equation, as described in ASTM F - 2094 standard, under applied loads of $98 \mathrm{~N}$. Fracture resistance plotted as a function of 'healing' particles composition.

must be met. These criteria involve experimental reproducibility, reliability of the test, monotonic introduction of a sharp crack, a known stress as a result of the application of external load and minimal uncertainties in the calibration equations. These criteria are met by standard bending test methods, such as single edge notched bends (SENB), but not typically in the case of indentation testing. Measuring fracture toughness by indentation, therefore has met some criticism in the literature over the years, showing that it is not a reproducible method giving straightforward information about the crack geometry. It has been pointed out that the residual stress factor is not constant for different materials and can decay with time. Moreover, the indentation plastic zone acts as a compressed spring, such that the force reduces with crack extension. As a result, empirical calibration constant vary for different materials and constitute the weak point of equations [29]. Additionally, models rely on examining surface cracks omitting whole network of three-dimensional cracks that interact which each other. Cracks generated by indentation are not controlled cracks, there is not a general cracking sequence, and therefore plastic damage zones do not always form in accordance to a model. Finally, measuring the crack tip is subjective, the results can vary between different labs, and even the microscopes used, which again reduces the reliability of the method for calculating absolute fracture toughness of materials [30]. In line with the above arguments, we state that the fracture toughness as measured by indentation cracking $\left(K_{I F R}\right)$ tends to overestimate the 'true' fracture toughness for ceramic materials as determined in SENB testing [29]. Consequently, the indentation fracture resistance calculations presented here are used merely to rank the samples based on fracture resistance to Vickers indentation under applied load of $98 \mathrm{~N}$ rather than to provide absolute fracture toughness values. Indentation fracture resistance, IFR, was calculated based on the measured lengths of diagonal cracks occurring in each direction from the indenter corners fitted into the equation proposed by Niihira [31,32]. Fig. 5 shows average values of a minimum of five indents. The highest values of IFR across the whole range of samples has been calculated for samples containing $\mathrm{B}$ additions. The sample containing $\mathrm{MoSi}_{2} \mathrm{AlB}$ shows a gradual increase in average IFR values from 3.9 to $4.6 \mathrm{MPa} \mathrm{m}^{1 / 2}$ with decreasing volumetric percentage of the dopant. The YPSZ $+\mathrm{MoSi}_{2} \mathrm{Al}$ sample have an average IFR of $3.9 \mathrm{MPa} \mathrm{m}^{1 / 2}$ across all doping concentrations showing the least variation between different volume fractions of healing particles. Samples containing $\mathrm{MoSi}_{2}$ show rather similar values of fracture resistance for different dopant concentration, varying from 3.3 (15 vol. $\%$ ) up to $4.4 \mathrm{MPa} \mathrm{m}^{1 / 2}$ (5 vol. \%). Larger variations in IFR for samples containing 15 vol. $\%$ of $\mathrm{MoSi}_{2}$ and sample containing 20 vol. $\% \mathrm{MoSi}_{2} \mathrm{~B}$ were observed. It is not exactly clear why samples containing the same fraction of embedded particles show relatively large error bars between average $K_{I F R}$ values. In general, embedded particles are more likely to influence the toughness via their interface properties than their inherent toughness, unless the cracks go through the particles preferentially. Indentation fracture resistance calculated for pure $\mathrm{MoSi}_{2}$ and pure YPSZ produced by SPS are 8.4 and $5.1 \mathrm{MPa}^{1 / 2}$, respectively. Crack - particle interactions are discussed further in the next section.

All the IFR values are scattered about 3.3-5.6 MPa $\mathrm{m}^{1 / 2}$, which is in a typical range of fracture toughness values reported for ceramic materials $[33,34]$. Since the differences in $K_{I F R}$ values are relatively small for the different systems it can be concluded that the addition of $\mathrm{Al}$ and $B$ to self - healing particles do not have a detrimental effect on the fracture mechanics of the composite material.

\subsection{Crack - particle interactions}

The trajectories of the indentation induced surface cracks have been investigated to find out whether there is a correlation between the path of the crack and the type and amount of healing particles. This, in turn, could help identifying an ideal content of healing particles in the self healing TBC material, choosing the concentration that promotes crack passing through the particle, which is the key requirement and starting point of the healing mechanism.

Fig. 6 shows an example of the intersect of the radial indentation induced cracks with the surface in a sample containing 5-20 vol. \% $\mathrm{MoSi}_{2}$. Images have been captured by SEM using the BSE detector to obtain a better image resolution. Cracks passing through the particles are frequently observed while cracks passing along a particle - interface are less frequent (unless that is geometrically the most likely propagation path). Similar observations have been made for the other healing particles, $\mathrm{MoSi}_{2} \mathrm{Al}, \mathrm{MoSi}_{2} \mathrm{~B}$ and $\mathrm{MoSi}_{2} \mathrm{AlB}$. Due to the texture of the YPSZ matrix appearing with an uneven contrast under the BSE detector it can be challenging to determine all the particles within the matrix, and in turn, establishing if crack is passing through the particle. As a result, cracked areas were also characterised by EDS to examine crackparticle interactions. Fig. 7 shows an example of an EDS map collected from the sample surface in the inset in Fig. 6a, showing a crack passing through a relatively large and well - defined particle. The map confirms that the magnified area contains a particle made of Mo and Si surrounded by a $\mathrm{Zr}$ - rich matrix. It is evident that on average the cracks tend to pass through particles that lie on the crack trajectory generally being neither attracted towards, or deflected from, the particles. As is to be expected, the number of particle interactions per mm of crack length increases with the volume fraction of embedded particles, as will be analysed in more detail below. Although cracks such as those reordered in Fig. 6 do not reveal the crack - particle interaction in the bulk (i.e. below the surface) we assume that the surface features are sufficiently representative of the bulk behaviour. In order to quantify the crack particle interactions the overall lengths of cracks have been calculated based on image anaylsis (IA) and the total number of interactions between cracks and particles has been counted. The average crack lengths (developed under applied load in this study) for samples with various volume fraction and chemistry of healing particles (i.e. $\mathrm{MoSi}_{2}, \mathrm{MoSi}_{2} \mathrm{Al}$, $\mathrm{MoSi}_{2} \mathrm{~B}$ and $\mathrm{MoSi}_{2} \mathrm{AlB}$ ) are as follows: $107 \mu \mathrm{m}( \pm 22) ; 110 \mu \mathrm{m}( \pm 18)$; $123 \mu \mathrm{m}( \pm 16)$ and $122 \mu \mathrm{m}( \pm 20)$ for $5,10,15$ and 20 vol.\% $\mathrm{MoSi}_{2}$, respectively. Numbers in brackets represent standard deviations indicating an insignificant difference between cracks lengths across different volume fractions of the particles analysed here. The outcome of the IA of the composite materials as a function of volume fraction of the particulates is plotted in Fig. 8. It shows the average number of intersects per crack (intersects here represent crack - particle intersections, which were accounted as " 1 " if a crack passed through the particle and " 0.5 " if through particle - matrix interface) as a function of volume fraction of healing particles. As one would expect, there is a clear increase in number of particles that interact with a single crack with an increase of volumetric percentage of healing particles embedded in the 

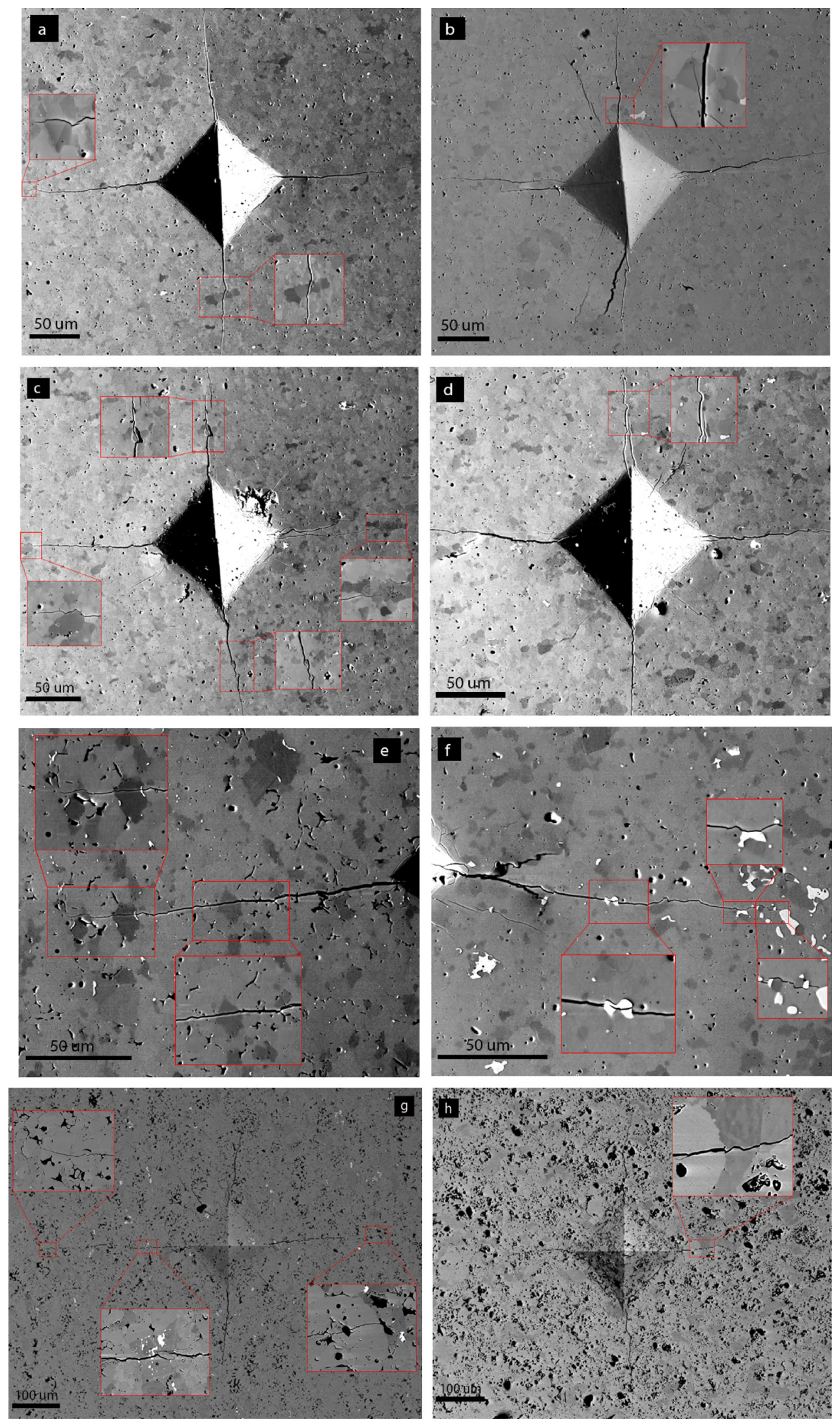

Fig. 6. SEM images of cracks propagating through bulk composite SPS samples containing: (a-b) 5, (c-d) 10, (e-f) 15 and (g-h) 20 vol.\% of MoSi 2 . Insets show magnified areas where cracks pass through the particles. 


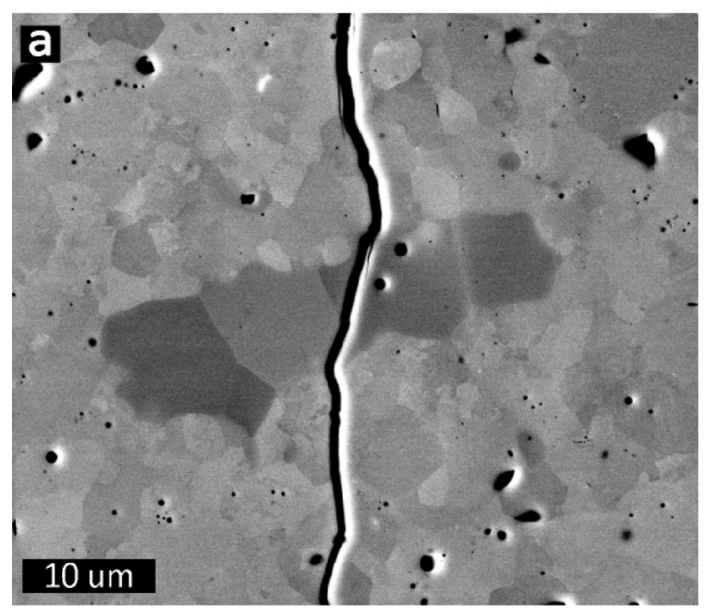

$\operatorname{Zr} \operatorname{L} \alpha 1$

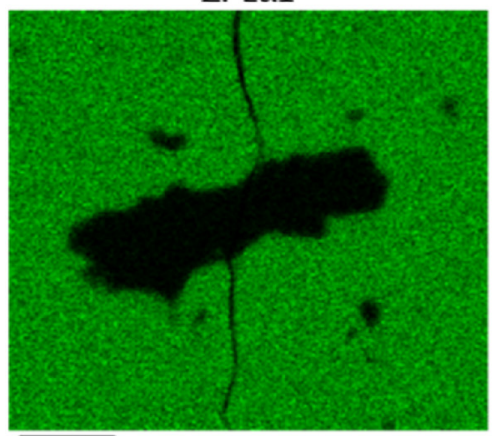

$\longdiv { 1 0 \mu \mathrm { m } }$

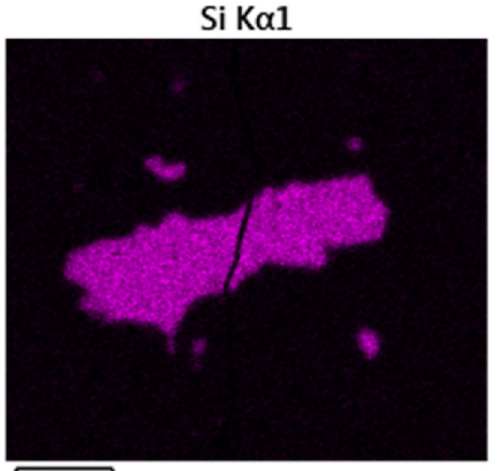

$10 \mu \mathrm{m}$
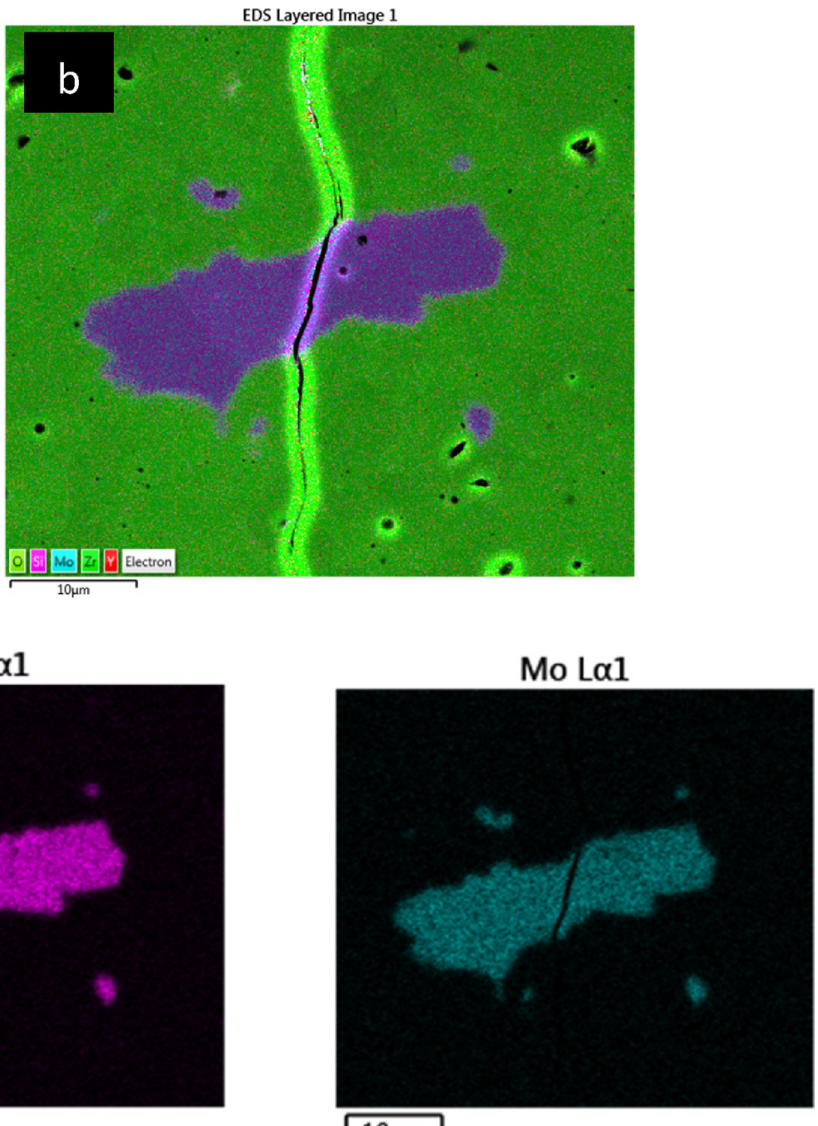

$\widehat{10 \mu \mathrm{m}}$

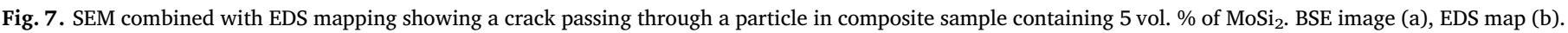

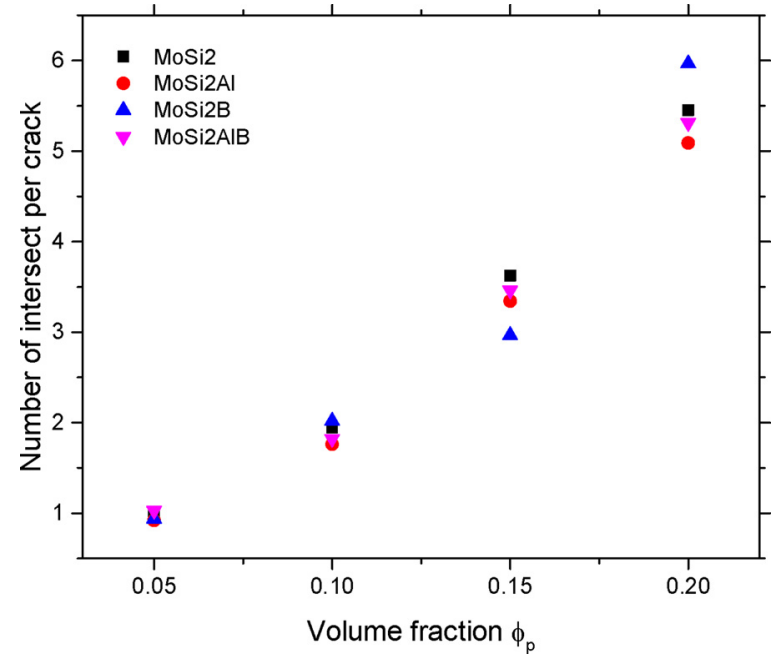

Fig. 8. Quantified crack - particle incidents as a function of volume fraction of particles having different chemical compositions embedded in YPSZ matrix.

YPSZ matrix. As the fraction of the particles increases the segmental crack length (i.e. the average length of the crack between two intersected particles along the crack) decreases. The most significant drop in segmental crack length as a function of the embedded particle fraction is seen between 5 and $10 \mathrm{vol}$. \% of embedded particulate. From this, it can be concluded that the minimal volume fraction of healing particles should be over $5 \%$.

There is no obvious correlation between the calculated indentation fracture resistance and the number of interactions between generated cracks and embedded particles for samples containing different volume
Table 3

Ratio of crack - particle to crack - interface preferable paths in samples containing different volume fraction of embedded particles of various chemical compositions.

\begin{tabular}{ccccc}
\hline \multirow{2}{*}{$\begin{array}{c}\text { Volume fraction (\%) of embedded } \\
\text { particles }\end{array}$} & \multicolumn{4}{c}{ Particle - to - interface ratio } \\
\cline { 2 - 5 } & $\mathrm{MoSi}_{2}$ & $\mathrm{MoSi}_{2} \mathrm{Al}$ & $\mathrm{MoSi}_{2} \mathrm{~B}$ & $\mathrm{MoSi}_{2} \mathrm{AlB}$ \\
\hline 5 & $1: 2$ & $1: 2$ & $1.5: 1$ & $1: 1$ \\
10 & $1: 1.7$ & $1: 1.7$ & $1.5: 1$ & $1: 1$ \\
15 & $1: 1.3$ & $1: 1$ & $1.5: 1$ & $1: 1.5$ \\
20 & $1: 1$ & $1: 1.5$ & $1.5: 1$ & $1: 1$ \\
\hline
\end{tabular}

fraction of particles and their chemical composition. However, if we look at the number of occurrences in which a crack is passing through a particle or along the particle - matrix interface some differences could be distinguished between the composites containing particles of different chemical composition. Table 3 shows cracks passing through particle - to - interface ratio for samples characterised in this work. It is clear that preferential crack pathway through the particle is most evident in samples containing $\mathrm{MoSi}_{2} \mathrm{~B}$ particles, i.e. suggesting that the interface is rather strong in comparison to the particle - matrix interface. This $\mathrm{MoSi}_{2} \mathrm{~B}$ containing sample showed the highest indentation fracture resistance values across all volume fractions of particles embedded in YPSZ matrix. This may suggest that increased values may be attributed to influence of the $\mathrm{MoSi}_{2}$ particles, which have been measured to have higher indentation fracture resistance than YPSZ matrix. The remaining samples shows either no preferential crack pathways, i.e. equal number of occurrences in which crack passes through particle or at particle grain boundaries (sample embedded with $\mathrm{MoSi}_{2} \mathrm{AlB}$ ) or cracks tend to go through the particle - matrix interface (samples embedded with $\mathrm{MoSi}_{2}$ or $\mathrm{MoSi}_{2} \mathrm{Al}$ ). 


\section{Conclusions}

Thermo - mechanical analysis has shown that the thermal expansion mismatch between the YPSZ matrix and the pure and alloyed $\mathrm{MoSi}_{2}$ particles is small. This is important because it will prevent the particles cracking on thermal cycling and means the CTE of the composite containing up to $20 \mathrm{vol}$. $\%$ of $\mathrm{MoSi}_{2}$ particles is similar to that of a conventional YPSZ TBC. Consequently, the inclusion of $\mathrm{MoSi}_{2}$ particles will not result in an increased thermal mismatch between the ceramic top coating and the $\mathrm{Ni}$ - based superalloys.

Indentation fracture resistance values of the composite materials are close to that obtained for pure YPSZ almost irrespective of the type of $\mathrm{MoSi}_{2}$ particle and the loading fraction. This suggests that the addition of self - healing particles does not significantly improve, nor reduce, the mechanical properties of the TBCs over the studied range. There is a weak indication that IFR values tend to be higher in samples that show a crack pathway passing through a larger number of particles.

Unsurprisingly, crack - particle interactions are more evident in composites containing higher volumes of particulates, and this reduces the segmental crack length to be healed by an individual particle. Overall, the crack path was to be found to be unaffected by the presence of the particles and to remain more or less planar. Minor differences in the relative fraction of cracks passing through the particle or along the particle interface were observed for composites containing B alloyed $\mathrm{MoSi}_{2}$ particles. The crack - particle interaction studies suggest that for the SPS produced composite materials studied here, at least 5 vol. \% particles, should be present to enable effective high temperature healing.

\section{Acknowledgments}

This project has received funding from European Union Seventh Framework Programme (FP7/2007-2013) under grant agreement no 309849, SAMBA (website: www.sambaproject.eu). Professor Philip J. Withers is grateful for a European Research Council for funding COREL - CT under grant No 695638.

\section{References}

[1] A.G. Evans, D.R. Clarke, C.G. Levi, The influence of oxides on the performance of advanced gas turbines, J. Eur. Ceram. Soc. 28 (2008) 1405-1419.

[2] B. Heeg, V.K. Tolpygo, D.R. Clarke, Damage evolution in thermal barrier coatings with thermal cycling, J. Am. Ceram. Soc. 94 (S1) (2011) S112-S119.

[3] K.W. Schlichting, N.P. Padture, E.H. Jordan, M. Gell, Failure modes in plasmasprayed thermal barrier coatings, Mater. Sci. Eng. A 342 (2003) 120-130.

[4] R. Vassen, M.O. Jarligo, T. Steinke, D.M. Mack, D. Stöver, Overview on advanced thermal barrier coatings, Surf. Coat. Technol. 205 (2010) 938-942.

[5] W.G. Sloof, Self healing in coatings at high temperatures, Self Healing Materials, Springer, The Netherlands, 2007, p. 390.

[6] A.L. Carabat, S. van der Zwaag, W.G. Sloof, Creating a protective shell for reactive $\mathrm{MoSi}_{2}$ particles in high-temperature ceramics, J. Am. Ceram. Soc. 98 (8) (2015) 2609-2616.

[7] Z. Derelioglu, A.L. Carabat, G.M. Song, S. van der Zwaag, W.G. Sloof, On the use of B-alloyed $\mathrm{MoSi}_{2}$ particles as crack healing agents inyttria stabilized zirconia thermal barrier coatings, J. Eur. Ceram. Soc. 35 (2015) 4507-4511.

[8] S. Maloy, A.H. Heuer, J. Lewandowski, J. Petrovic, Carbon additions to molybdenum disilicide: improved high-temperature mechanical properties, J. Am.
Ceram. Soc. 74 (10) (1991) 2704-2706.

[9] M. Nakamura, S. Matsumoto, T. Hirano, Elastic constants of $\mathrm{MoSi}_{2}$ and $\mathrm{WSi}_{2}$ single crystals, J. Mater. Sci. 25 (1990) 3309-3313.

[10] S.R. Srinivasan, R.B. Schwarz, Elastic moduli of $\mathrm{MoSi}_{2}$-based materials, J. Mater. Res. 7 (7) (1992) 1610-1613.

[11] R.K. Wade, J.J. Petrovic, Fracture modes in $\mathrm{MoSi}_{2}$, J. Am. Ceram. Soc. 75 (6) (1992) 1682-1684.

[12] L. Donzel, S.G. Roberts, Microstructure and mechanical properties of cubic zirconia (8YSZ)/SiC nanocomposites, J. Eur. Ceram. Soc. 20 (2000) 2457-2462.

[13] M. Mazaheri, Z. Razavi Hesabi, F. Golestani-Fard, S. Mollazadeh, S. Jafari, S.K. Sadrnezhaady, The effect of conformation method and sintering technique on the densification and grain growth of nanocrystalline $8 \mathrm{~mol} \%$ yttria-stabilized zirconia, J. Am. Ceram. Soc. 92 (5) (2009) 990-995.

[14] J. Kulczyk-Malecka, X. Zhang, J. Carr, A.L. Carabat, W.G. Sloof, S. van der Zwaag, F. Cernuschi, F. Nozahic, D. Monceau, C. Estournès, P.J. Withers, P. Xiao, Influence of embedded $\mathrm{MoSi}_{2}$ particles on the high temperature thermal conductivity of SPS produced yttria-stabilised zirconia model thermal barrier coatings, Surf. Coat Technol. 308 (2016) 31-39.

[15] D. Koch, G. Mauer, R. Vassen, Manufacturing of composite coatings by atmospheric plasma spraying using different feed-stock materials as YSZ and $\mathrm{MoSi}_{2}$, J. Therm. Spray Technol. 26 (2017) 708-716.

[16] M.K. Meyer, M. Akinc, Oxidation behaviour of boron-modified $\mathrm{Mo}_{5} \mathrm{Si}_{3}$ at $800^{\circ}-1300^{\circ} \mathrm{C}$, J. Am. Ceram. Soc. 79 (4) (1996) 938-944.

[17] L. Portebois, S. Mathieu, Y. Bouizi, M. Vilasi, S. Mathieu, Effect of boron addition on the oxidation resistance of silicide protective coatings: a focus on boron location in as-coated and oxidised coated niobium alloys, Surf. Coat. Technol. 253 (2014) 292-299.

[18] A. Bjorneklett, L. Haukeland, J. Wigren, H. Kristiansen, Effective medium theory and the thermal conductivity of plasma-sprayed ceramic coatings, J. Mater. Sci. 29 (1994) 4043-4050.

[19] B. Nait-Ali, K. Haberko, H. Vesteghema, J. Absi, D.S. Smith, Thermal conductivity of highly porous zirconia, J. Eur. Ceram. Soc. 26 (2006) 3567-3574.

[20] K.W. Schlichting, N.P. Padture, P.G. Klemens, Thermal conductivity of dense and porous yttria-stabilized zirconia, J. Mater. Sci. 36 (2001) 3003-3010.

[21] S.A. Ponnusami, S. Turteltaub, S. van der Zwaag, Cohesive-zone modelling of crack nucleation and propagation in particulate composites, Eng. Fract. Mech. 149 (2015) $170-190$.

[22] P.J. Withers, Elastic and thermoelastic properties of brittle matrix composites, in: E.S. Hashmi (Ed.), Reference Module in Materials Science and Materials Engineering, Elsevier, Oxford, 2016, pp. 1-18.

[23] K.H. Kerner, The elastic and thermo-elastic properties of composite media, Proc. Phys. Soc. Sec. B 69 (8) (1956) 808.

[24] R.A. Schapery, Thermal expansion coefficients of composite materials based on energy principles, J. Compos. Mater. 2 (3) (1968) 380-404.

[25] P.S. Turner, Thermal-expansion stresses in reinforced plastics, J. Res. Nat. Bur Stand. 37 (1946) 239-250.

[26] J.J. Petrovic, R.E. Honnell, Partially stabilized $\mathrm{ZrO} 2$ particle-MoSi ${ }_{2}$ matrix composites, J. Mater. Sci. 25 (10) (1990) 4453-4456.

[27] F. Nozahic, D. Monceaua, C. Estournès, Thermal cycling and reactivity of a $\mathrm{MoSi}_{2} /$ $\mathrm{ZrO}_{2}$ composite designed for self-healing thermal barrier coatings, Mater. Des. 94 (2016) 444-448.

[28] R. Morrell, Fracture toughness testing for advanced technical ceramics: internationally agreed good practice, Adv. Synth. Catal. 105 (2006) 88-98.

[29] G.D. Quinn, R.C. Bradt, On the Vickers indentation fracture toughness test, J. Am. Ceram. Soc. 90 (3) (2007) 673-680.

[30] F. Sergejev, A. Maksim, Comparative study on indentation fracture toughness measurements of cemented carbides, Proc. Estonian Acad. Sci. Eng. 12 (4) (2006) 388-398.

[31] K. Niihara, R. Morena, D.P.H. Hasselman, Evaluation of 1Kic of brittle solids by the indentation method with low crack-to-indent ratios, J. Mater. Sci. Lett. 1 (1982) $13-16$.

[32] F2094-01, A.,(2003) Standard Specification for Silicon Nitride Bearing Balls, in Annual Book of Standards, West Conshohocken: PA.

[33] G.A. Gogotsi, Fracture toughness of ceramics and ceramic composites, Ceram. Int. 29 (2003) 777-784.

[34] M. Guazzato, M. Albakry, S.P. Ringer, M.V. Swain, Strength, fracture toughness and microstructure of a selection of all-ceramic materials. Part II. zirconia-based dental ceramics, Dent. Mater. 20 (2004) 449-456. 